\title{
LEADERSHIP B.S. - JEFREY PFEFFER E A INDÚSTRIA DA LIDERANÇA
}

\section{RESUMO}

"Desenvolver a capacidade de liderança" é uma constante na vida de profissionais interessados em atuar de forma mais assertiva nas organizações nas quais exercem suas atividades. Leadership BS é mais uma conquista de Jeffrey Pfeffer que nos obriga a repensar esses dogmas que a indústria da liderança, como assim a denomina o autor, nos empurram diariamente. Em um trabalho baseado na necessidade urgente de incorporar evidências a uma prática que pode causar prejuízos financeiros e diversos outros malefícios à sociedade, Pfeffer consegue demonstrar facilmente porque, por exemplo, alguns comportamentos tido como exemplares não passam de fábulas, que só existem em salas de aula e cursos de eficácia duvidosa - se, por eficácia, entender-se formar líderes melhores. O autor desafia seus leitores a repensarem a forma como atuam, entendendo que processos psicológicos como o viés de confirmação e o autoengano descaracterizam o formato desejado de liderança, aquele ensinado, mas não praticado.

Palavras-chave: Liderança; Gestão Baseada em Evidências, Líder.

\section{LEADERSHIP B.S. - JEFFREY PFEFFER AND LEADERSHIP INDUSTRY}

\begin{abstract}
"Developing leadership" is a constant search for professionals interested on acting in a more assertively in the organizations they perform their roles. Leadership BS is another endeavor by Jeffrey Pfeffer that makes us think over the tenets which the leadership industry, as the author refers to it, imposes to us daily. In a work based on the urgent need to incorporate evidence to a practice that could cause financial damage and other harmful consequences to the society, Pfeffer easily succeed on demonstrating why, for instance, some behaviors which are assumed as role models are nothing but fairy tales that only exist on classrooms and courses which efficacy is doubtful - if efficacy is understood as educating better leaders. The author challenges his readers to rethink the way they act, by understanding how psychological processes such as confirmation bias and self-deceiving reshape the wished format of leadership, which is taught, but nor practiced.
\end{abstract}

Keywords: Leadership; Evidence Based Management; Leader. 


\section{LEADERSHIP B.S. - JEFFREY PFEFFER Y LIDERAZGO DE LA INDUSTRIA}

\section{RESUMEN}

"Desarrollando liderazgo" é una busca constante por profesionales interesados en actuar de forma más afirmativa en las organizaciones en las cuales ellos hacen sus papeles. Leadership BS é otra conquista de Jeffrey Pfeffer que nos haz repensar los dogmas sobre los cuales la industria del liderazgo, como el autor se lo refiere a ella, nos impone diariamente. En un trabajo basado en la necesidad urgente de incorporar evidencias a una práctica que podría causar prejuicio financiero y otros detrimentos a la sociedad, Pfeffer fácilmente obtiene suceso en enseñar por que, por ejemplo, algunos comportamientos que se asume que son modelos, son en verdad nada además de cuentos de hada que solamente existen en clases y corsos con eficacia dudosa - si, por eficacia es entendida como obtener líderes mejores. El autor se los desafía a sus lectores a repensar la forma como ajen, por comprender cómo procesos psicológicos como el sesgo de confirmación y el auto engaño reforman el formato idealizado del liderazgo, que es el enseñado, pero no el practicado.

Palabras clave: Liderazgo; Gestión Basada en la Evidencia; Líder.

\footnotetext{
${ }^{1}$ Doutorando em Administração no Programa de Pós-Graduação em Administração da Universidade Nove de Julho PPGA/UNINOVE. Brasil. E-mail: leovils@icloud.com

${ }^{2}$ Doutorando em Administração no Programa de Pós-Graduação em Administração da Universidade Nove de Julho PPGA/UNINOVE. Brasil. E-mail: gusviegas@gmail.com
} 


\section{INTRODUÇÃO}

Liderança é um tema que vende.Vende livros, consultoria, blogs, palestras, treinamentos e especialização. Entretanto, segundo Pfeffer, o que a indústria da liderança vende não entrega,: não entrega ambientes de trabalho melhores, resultados ou conceitos passíveis de reprodução. Paradoxalmente, a indústria da liderança entrega aquilo que é procurado por seus clientes, consumidores ávidos do "feel good leadership literature"(Pfeffer, 2015, p. 222) como histórias de sucesso, casos de superação, fábulas inspiradoras, mantras motivacionais e a visão reconfortante de um mundo justo, um mundo que premia o trabalho duro e as boas intenções. Não seria exagerado dizer que a indústria da liderança tangencia a literatura de autoajuda, já que ambas compartilham os receituários prescritivos e a ausência de evidências que os suporte.

A indústria da liderança parece viver em um universo paralelo, utópico e ideal, permeado por boas intenções sobre as qualidades desejadas em um líder que recorrentemente são diferentes daquelas valorizadas no mundo real corporativo. Em que pese as boas intenções, seu receituário impreciso, pouco ou nada científico, pode trazer mais danos do que benefícios ao criar expectativas descasadas da realidade para aqueles que entram no mundo corporativo ou ao supervalorizar a contribuição de líderes para resultados sem a devida atenção às taxas base, ou seja, aos resultados que ocorreriam sem sua interferência.

Leadership B.S. não é libelo contra a indústria da liderança. Pfeffer reconhece a existência e atuação de profissionais bem preparados no meio, mas critica seu caráter normativo sem as devidas evidências que sustentem as prescrições, seu conteúdo que se assemelha à pregação, o foco na inspiração e, principalmente, sua falha em perceber que nos caminhos que levam à liderança as características preconizadas como ideais não necessariamente são desejadas. Para cada uma das características mais prescritas como modéstia, humildade, autenticidade ou servir os outros, Peffer apresenta seus pontos positivos, negativos e evidências sobre sua premência, ou não, no mundo corporativo. Apresenta também situações nas quais características preconizadas como fundamentais são efetivamente contraproducentes.

Pfeffer, em obra anterior com Robert Sutton (Pfeffer \& Sutton, 2013), toma como base a Medicina Baseada em Evidências para defender uma maior incorporação dos métodos científicos à gestão empresarial, nomeada como Gestão Baseada em Evidências. Leadership B.S. tem o mesmo apelo, e uma mensagem semelhante, não há remédio que tudo cure, elixires para todos os males ou prescrições de liderança para todos os contextos. Para cada "princípio ativo" de liderança não há apenas a posologia ou dose recomendada, há que se considerar os efeitos colaterais.
Consultamos o site de uma livraria no Brasil e encontramos cerca de 5.000 títulos de livros sobre liderança e líderes na categoria de Administração, Economia e Negócios. Como separar o joio do trigo? Liderar com base na Bíblia ou no Budismo? Com base em "21 leis irrefutáveis" ou em "52 práticas"? Tornarse um líder heroico ou sincero? Um coach grego ou um líder autêntico? Obama, Maquiavel ou Gorbachev? Há títulos para todos os gostos e divulgação nas mídias mais diversas chegando aos elevadores de prédios comercias e aos displays apresentando sob a forma de "gotas de sabedoria" frases como "liderar é colocar as pessoas certas no lugar certo", "fazer as perguntas certas", "usar as métricas certas", frases que poderiam facilmente ter saído de biscoitos da sorte.

Acreditamos que um primeiro passo peneirar o que realmente pode conduzir ao entendimento do fenômeno da liderança seja Leadership B.S., que apresentamos a seguir. Em nossa análise e incluímos referências da Psicologia Social em nossos comentários.

\section{O DIAGNÓTISCO DE PFEFFER}

Em uma crítica ao uso de vieses cognitivos como fonte de manipulação para o lançamento de produtos ou serviços potencialmente desnecessários ao bem-estar, Akerlof e Shiller (2015) argumentam que, enquanto houver oportunidades para manipulação, novos produtos serão lançados no mercado. Independentemente de boas intenções de executivos ou empreendedores, segundo os autores, oportunidades de mercado não ocupadas por uma empresa acabam sendo ocupadas por outras em uma espécie de círculo vicioso de manipulação e decepção no qual as vítimas são aqueles cujo livre arbítrio e capacidade de escolha racional formam o alicerce da teoria econômica clássica, os consumidores. A discussão sobre regulamentação, ou não, de atividades econômicas a partir de tais argumentos foge ao escopo de nossa análise, entretanto, a profusão de artigos, blogs, consultorias e treinamentos de liderança baseados preponderantemente no que Pfeffer chama de "fell good leadership literature", termo cunhado por Rajiv Pant (Pfeffer, 2015, p. 222), parece ir ao encontro da crítica de Akerlof e Shiller (2015). Enquanto houver clientes para prescrições reconfortantes, fábulas e líderes heroicos o mercado se encarregará de atrair novos fornecedores.

Um mercado caracterizado pela ausência de pesquisas rigorosas, de conhecimento científico e da necessidade de credenciais como o da indústria de liderança é um mercado com poucas barreiras à entrada (Porter, 2004), um mercado onde histórias de sucesso ecoam como se pudessem ser repetidas na prática. Além das poucas barreiras, a indústria da liderança carece de avaliações apropriadas. Seminários e treinamentos são avaliados com base em escalas de 
satisfação muito embora as evidências em ambientes de ensino apontem que a satisfação com o professor não tenha correlação significante com o aprendizado. Nesse ponto Pfeffer é taxativo ao lembrar que o problema com as mensurações incorretas é que você tem o resultado daquilo que se mensura. Mensura-se entretenimento, tem-se entretenimento. Ou seja, o melhor professor não é necessariamente o que foi melhor avaliado, mas é certamente o que mais entreteve seus alunos, em alguns casos.

Em Leadership B.S. Pfeffer argumenta que a análise de como os líderes falham, e, segundo o autor, falham recorrentemente, pode ser feita sob duas óticas: pela teoria das maçãs podres ou por uma investigação sistemática do processo de formação de líderes. A teoria das maçãs podres é baseada em falhas das empresas em recrutar ou das universidades em formar agentes que não sabem, ou não souberam, se comportar eticamente e que acabaram por contaminar o ambiente. Identificando e expurgando o agente com o desvio de conduta cessa-se o problema. A investigação sistemática do processo de formação de lideranças, por outro lado, tem seu foco nos traços que fazem líderes de sucesso, muitas vezes diferentes dos traços desejados, que acabam sendo valorizados nas organizações, a despeito de seu potencial efeito negativo, e não mensurado, nos ambientes de trabalho. Pfeffer adota a segunda abordagem ao longo do livro.

Um dos pontos falhos da indústria da liderança, segundo Pfeffer, é que os traços desejados nas pessoas em cargos de liderança dificilmente são aqueles que ajudaram a mesma pessoa a galgar os degraus da hierarquia organizacional. O líder autêntico de hoje pode ter sido o inautêntico ontem, o servidor o carrasco, o modesto o arrogante, o verdadeiro o falso. O que é desejado em uma posição de liderança não necessariamente está em linha com aquilo que foi desejável e valorizado no caminho em direção ao topo. Dois pontos abordados em "Hard Facts, Dangerous Half Truths..(Pfeffer \& Sutton, 2013) contribuem para esse descasamento: o benchmarking casual, ou seja, a identificação de características aparentes sem a atenção devida ao contexto e ao processo que as fizeram valorizadas; e o pensamento de que o que deu certo no passado ou em outra empresa é transferível para que se alcance o sucesso em outra. Esses dois pontos acabam por reforçar o caráter normativo da indústria da liderança, líderes devem agir assim, fazer isso, se comportar dessa maneira e dessa forma terão sucesso. Fazendo um paralelo com a medicina, Pfeffer afirma que é difícil concebermos que alguém sem as qualificações e credenciais necessárias venha a desenvolver uma intervenção ou tratamento médico e que saia mundo afora ensinando como praticar a medicina (Pfeffer, 2015, p. 33). O que é impensável na medicina é o comum em liderança.

O diagnóstico de Pfeffer é que, a despeito de mais de 40 anos de existência, de milhares de profissionais treinando, orientando, inspirando e motivando líderes atuais e futuros, a indústria de liderança falhou retumbantemente, líderes falham, ficam pouco tempo em seus cargos, empresas quebram, ambientes de trabalho ainda são mais tóxicos do que agradáveis, funcionários desengajados e desmotivados são a regra e não a exceção, novos escândalos aparecem a todo momento, e todo esse processo não poderia ser explicado apenas por maçãs podres, ou pomares podres.

\section{SOBRE FÁBULAS E INSPIRAÇÃo}

Sob a ótica da psicologia evolucionista, teoria com a qual Pfeffer flerta em algumas partes do livro, liderança tem um apelo evolutivo. Módulos mentais selecionados ao longo de nosso passado ancestral para a solução de problemas recorrentes deram origem a comportamentos inconscientes distintos que são gerados a partir da ativação de um módulo ou de outro. Dentre os módulos mentais que dispomos, o de ascendência em um grupo social é relacionado com a liderança. Em grupos de animais o macho, ou fêmea, alfa é o primeiro a comer e tem a prerrogativa de escolher a (o) parceira (o) em troca da condução do grupo (Forgas, Fiedler, \& Sedikides, 2012, p. 23). Ascender em um grupo de homo sapiens, seja na savana, seja nas corporações, traz benefícios semelhantes em termos de status. Nem todos vão ascender, nem todos buscam ascensão, há aqueles que irão se beneficiar da proteção do grupo e que seguirão a liderança sem contestá-la. Entretanto, a vida em grupo e o status de cada um em relação ao grupo em que está inserido, disparam em nós, seres humanos do século $\mathrm{XXI}$, os mesmos módulos mentais que disparavam em nossos ancestrais caçadores e coletores. Participar de um grupo é bom, liderá-lo é ainda melhor. Possivelmente, o simples fato de sermos animais sociais seja uma das causas do apelo que a liderança exerce em cada um de nós. Onde existe apelo existe mercado, onde existe mercado existe oportunidade, onde existe oportunidade existem fornecedores.

Fábulas inspiram. Em fábulas o bem triunfa, o mundo é justo e moral e o trabalho é recompensado. $\mathrm{O}$ problema com as fábulas é que não passam de fábulas, e mesmo os auto relatos, muitas vezes heroicos, de líderes sobre sua trajetória, não passam de racionalizações, de confabulações em busca da coerência, ainda que inconscientemente.

Tendemos a pensar que a memória reproduz fielmente uma realidade passada como gravada em um DVD (Squire \& Kandel, 2009). Acontece que uma melhor analogia para a memória é a de um computador. Enquanto estamos trabalhando em uma tarefa como ao escrever esse texto, por exemplo, usamos a memória RAM, equivalente à memória de curto prazo e, se sairmos do processador de texto sem gravar o 
conteúdo, o que foi escrito é perdido. A gravação do conteúdo no disco rígido do computador, ou na nuvem, equivale ao armazenamento na memória de longo prazo. A cada mudança que fazemos no texto e gravamos estamos alterando o conteúdo armazenado e após sucessivas modificações o conteúdo final pode ser bastante diferente do inicial. Assim também é a memória, a cada vez que evocamos uma memória armazenada, ao trazê-la para nossa "área de trabalho", estamos fazendo com que ela interaja com outros pensamentos e com estímulos do ambiente, ou seja, o simples fato de evocar uma memória potencialmente a modifica.

A falibilidade da memória e a busca por coerência, embora não tratados por Pfeffer, complementam seu argumento sobre autoengano com base nos estudos do psicólogo evolucionista Robert Trivers (Trivers, 2000, 2010; von Hippel \& Trivers, 2011). O autoengano, segundo a teoria, tem como uma das funções o fato de que ao mentir para nós mesmos e nos convencermos temos mais chance de mentir para os outros e sermos convincentes. Uma outra função é que diante de um mundo imprevisível, injusto e incoerente o autoengano não só nos ajuda a viver, ao não atentarmos para todas as dificuldades, como é fundamental para a ultrapassarmos obstáculos. Autoengano é assim uma lente que nos permite ver o mundo de uma maneira mais favorável à nossa sobrevivência.

Ao juntarmos os elementos da falibilidade da memória, da busca por coerência e do autoengano e o viés da confirmação, nossa tendência a encontrar evidências que sustentem nossas crenças (Kahneman, 2012), temos o fio condutor das histórias heroicas de liderança. Supondo uma primeira pessoa: sou um líder, cheguei aqui; minha trajetória precisa ser coerente com o que é esperado de um líder, logo me lembro das características valorizadas (viés da confirmação) e modifico minhas memórias; me fazendo acreditar que mereço estar onde estou e me facilitando mostrar aos outros porque mereço (autoengano), o que torna minha história coerente; e assim sucessivamente. Para quem é exposto às trajetórias, esse meio termo entre história e fábula, a busca por coerência (ele (a) está lá então deve ter algo de bom), o autoengano (eu também posso) e o viés da confirmação (vejo essas características em mim) completam o ciclo entre o emissor e o receptor.

Liderança nos atrai, e ao sermos atraídos buscamos coerência com nossas crenças e usando filtros cognitivos. Uma vez coerentes nos inspiramos auto enganados e nos vemos capazes de liderar. O problema é que a inspiração é efêmera e sujeita aos choques de realidade do dia-a-dia. Inspiração não é mensurável, o que provavelmente explica, segundo Pfeffer, porque escolas de medicina, arquitetura e engenharia não costumam se basear em fábulas inspiradoras, mas em dados e em métodos científicos.

A influência doa líder na motivação, engajamento e comprometimento de funcionários e em sua mudança de comportamento é, na indústria da liderança, supervalorizada. Líderes inspiradores, modestos, autênticos, servidores e que falam a verdade, quase super-heróis autodeclarados ou declarados por terceiros, são tidos como a principal fonte de mudança nas organizações, a despeito de evidências de pessoas desmotivadas e desengajadas e da existência de ambientes de trabalho tóxicos sob essa mesma liderança. A indústria da liderança ignora a vasta literatura da Psicologia Social, Psicologia Evolucionista e da Economia Comportamental a respeito da influência do priming, exposição a estímulos antes de uma decisão ou avaliação, framing, maneira como um contexto é enquadrado, tradicionalmente como ganho ou perda, e conformidade com grupos na mudança de comportamento.

Funcionários de uma empresa aumentam as contribuições para a caixinha do café nos dias em que um quadro com olhos está na parede em comparação com os dias em que um quadro de uma paisagem está pendurado, efeito do priming na mudança de comportamento (Bateson, Nettle, \& Roberts, 2006). Preferimos, em função de nossa aversão à perda, uma proteína $90 \%$ livre de gordura à mesma proteína com $10 \%$ de gordura embora sejam a mesma coisa, efeito do framing na mudança de comportamento (Kahneman, 2012). Pesquisadores testando em uma cadeia de hotéis mensagens a respeito da preservação do meio ambiente e a quantidade de toalhas usadas pelos hóspedes, descobriam que a mensagem com maior efeito, fazendo com que os hóspedes usassem a mesma toalha por mais dias, dizia que aquele que se hospedaram naquele mesmo apartamento reutilizaram as toalhas de banho (Goldstein, Cialdini, \& Griskevicius, 2008). Fazemos parte de grupos dos quais nem imaginamos. Efeito da conformidade com o grupo na mudança de comportamento.

Ao ignorar as evidências de áreas do conhecimento ligadas ao estudo do comportamento humano a indústria da liderança continua a bater na mesma tecla, o líder, como em um samba de uma nota só.

\section{MEUS TRAÇOS E MEU SUCESSO, O CONTEXTO DE MEU FRACASSO, E O INVERSO PARA VOCÊ}

Modéstia, humildade, autenticidade, falar a verdade e servir os outros são, sem dúvida, características desejáveis e normalmente valorizadas nas interações sociais. Empresas são ambientes sociais nos quais pessoas convivem, interagem, cooperam, disputam, lideram e são lideradas. Os problemas principais com as prescrições da indústria da liderança sobre tais características, segundo Pfeffer, são que o desejável em certos contextos pode ser indesejável em outros e que as características de quem está na 
liderança nem sempre são as mesmas que os levaram à liderança.

Citando os "líderes de nível 5" definidos por Collins (Collins, 2011) como aqueles que preferem falar sobre as empresas e as contribuições dos outros ao invés de falar sobre si mesmo, Pfeffer reconhece a importância da modéstia e humildade ressaltando, contudo que dificilmente os modestos e humildes se tornam líderes. Líderes modestos e humildes ao reconhecerem as contribuições dos outros e dividirem os méritos ajudam a criar ambientes mais participativos e engajados em que as pessoas se sentem importantes, reconhecidas e recompensadas.

Pfeffer faz um paralelo com o Marketing e a venda de produtos para explicar como ser narcisista, oposto da modéstia, pode ajudar a ascender na carreira. Narcisistas demonstram autoconfiança e são mais persuasivos, tem comportamento empreendedor, tomam decisões mais agressivas e tendem a ser admirados no curto prazo. Narcisistas, são como produtos em destaque nas prateleiras ou vitrines. O que não é visto, pode não ser lembrado e o que não é lembrado não é comprado, ou promovido.

Tendemos a não admirar aqueles que se auto enaltecem e que gostam de se sobressair, o holofote no líder ofusca os subordinados, assim, se por um lado os narcisistas se vendem bem, e ganham em média mais que os modestos, por outro tendem a causar desconforto e desmotivação nas equipes. Como explicar, então, o paradoxo de líderes narcisistas como Bill Gates, Jack Welch e Steve Jobs serem aceitos e aclamados? O viés da confirmação, comentado anteriormente, pode explicar a tendência a identificarmos a modéstia nos líderes narcisistas. Acreditamos que a modéstia é uma característica desejável nos líderes, Bill Gates, Jack Welch e Steve Jobs, são, ou foram, exemplos de líderes de sucesso, logo identificamos neles as características que desejamos. Uma outra possibilidade é o efeito halo, a transferência de julgamentos de uma esfera para outra (Rosenzweig, 2014). Julgamos a Microsoft, a GE e a Apple como empresas de sucesso e transferimos para seus líderes aquilo que acreditamos ser características de empresas de sucesso como bons lugares para se trabalhar, preocupação com clientes e ações genuinamente responsáveis, características mais alinhadas com a modéstia e humildade de seus líderes do que com o narcisismo.

O que se aplica à modéstia não é diferente quando pensamos na autenticidade e em falar a verdade. Ser autêntico é bom, inspira confiança e não traz surpresas. Acontece que líderes nem sempre são chamados a demonstrar sua autenticidade, o show tem que continuar e para que continue, por vezes, a encenação é a regra. Demonstrar as emoções é inadequado a situações em que as mesmas devem ser controladas. Funcionários da Disney sorriem, vendedores são simpáticos, líderes não podem se dar ao luxo de evitar de stakeholders de quem não gostam e clientes chatos também tem razão. Nosso humor ou emoções não são convidados de honra no palco organizacional. Há nas empresas uma espécie de acordo tácito, praticamente um mantra, de que problemas pessoais ficam no estacionamento levando, nas palavras de Pfeffer ao conceito de inautenticidade útil:

"Ser verdadeiro a seu respeito só é útil
enquanto as suas características forem
aquelas que levam as pessoas ao sucesso.
Caso contrário, as pessoas devem encarnar as
características e qualidades requeridas de
forma a se apresentarem da melhor forma
possível"(Pfeffer, 2015, p. 96) - tradução dos
autores

Em suma, não basta ser líder, é preciso parecer líder a despeito das circunstâncias;

Seres humanos mentem embora valorizem a verdade. Seres humanos mentem na medida em que as mentiras não comprometam a visão que têm a respeito de si mesmos (Ariely, Bracha, \& Meier, 2009), mentem por "causas nobres" e por interesse próprio. Contextos e estímulos do ambiente aumentam a tendência a mentirmos. Estudantes usando óculos originais de marcas de luxo pensando que eram falsificados aumentaram suas notas ao conferir as respostas de um teste (Ariely,dan, [s.d.]). Mentimos para preservar relacionamentos, para evitar tensões e conflitos, para exagerar nossas qualidades, os currículos que o digam, para agradar, para não desagradar, mentimos para nós mesmos para mentirmos melhor para os outros (Trivers, 2000). Se todos mentem no dia-a-dia é razoável inferirmos que nas empresas não é diferente.

Práticas de mercado nem sempre são baseadas em falar a verdade. Empresas mentem para os funcionários, sob a desculpa de não causar desmotivação, sobre suas oportunidades de crescimento profissional, anunciam produtos ainda não disponíveis para evitar a perda de mercado para inovações em produtos concorrentes, e omitem defeitos de fabricação rotulando o recall como um exemplo de honestidade e preocupação com os clientes. Se não são práticas de mercado comuns não há como dizer que não ocorrem. É provável que maçãs podres sejam responsabilizadas pelos dispositivos que fraudavam testes de poluentes em carros de uma montadora ("Auto Esporte - Volkswagen admite que 11 milhões de carros têm software que frauda testes", [s.d.]), entretanto, é difícil saber a contribuição da omissão da verdade no episódio.

Pfeffer ressalta que a mentira traz poucos efeitos adversos citando exemplos de executivos que depois de cumprir penas por práticas ilegais ainda conseguiam empregos bem remunerados, de uma celebridade, que já cumpriu pena por usar informações 
Leadership B.S. - Jefrey Pfeffer e a Indústria da Liderança

privilegiadas, que continua com um programa na TV, e ainda trocou de patrocinador no meio de um contrato vigente sem afetar seu status de celebridade. Adicionamos aos exemplos de Pfeffer o caso do Dr. $\mathrm{Oz}$, médico celebridade com programa na TV americana, e com lançamento previsto no Brasil, que foi levado à corte e proibido de anunciar seus produtos como "milagrosos", uma mentira reforçada pelo argumento da autoridade, e que em razão da alta audiência continua com o programa. Recorrendo Akerlof e Shiller (2015), enquanto houver espaço para a mentira, a mentira será vendida.

Servir aos outros faz sentido no ambiente de negócios. Líderes que focam no bem estar de seus funcionários, em suas necessidades, e que colocam seus os interesses de sua equipe acima dos interesses da organização promovem motivação, engajamento e comprometimento. Pfeffer cita os exemplos de Richard Branson, Virgin Atlantic Airlines, e de Herb Kelleher, Southwest Airlines, como líderes que construíram organizações com foco no bem-estar de seus funcionários. Entretanto, Herb e Branson são exceções, líderes chegam a ganhar 330 vezes mais que um funcionário médio e essa diferença não para de crescer (Frank, 2012). Pessoas com cargos de liderança têm, em muitas empresas, restaurantes diferentes, vagas melhores para seus carros, entre outros instrumentos de diferenciação. Líderes tem parte expressiva de seus rendimentos atrelados à performance, ou seja, a preocupação com os interesses dos funcionários, em geral, não é levada em consideração. Pfeffer, ressaltando a importância dos interesses dos funcionários, recorre à Teoria da Agência, que diz respeito ao conflito de interesses entre o proprietário e o agente contratado para representa-lo, para recomendar que a remuneração dos líderes deveria estar atrelada à mensuração do bem-estar dos funcionários. Ao normatizar a preocupação com o interesse dos outros as empresas estariam neutralizando o auto interesse, princípio do conflito da Teria da Agência, em seus gestores.

O que é dito pelos líderes, ou por seus promotores, a respeito de sua trajetória é diferente do caminho percorrido. Como já abordado, a memória é reconstruída e a cada reconstrução se afasta mais da memória original. Ao contarem suas histórias, o viés da confirmação ajuda a encontrar aquilo que é desejável ser encontrado. Aos dois fenômenos cognitivos adicionamos a Teoria da Atribuição, segundo a qual as análises que fazemos a nosso respeito são distintas das que fazemos a respeito dos outros (Moskowitz, 2013). O meu sucesso é função dos meus traços, de minhas características como perseverança, visão e integridade, enquanto os meus eventuais fracassos são fruto do contexto, da falta de sorte, de coisas que me fugiam ao controle. Em contrapartida, o sucesso dos outros é função do contexto, dos ventos favoráveis e da sorte, enquanto seu fracasso decorre dos traços como fraqueza ou negligência. Histórias de líderes são, assim, histórias de superação, envolvimento, comprometimento, histórias em que o acaso e a sorte não fazem parte.

\section{CONCLUSÃO}

Pfeffer sugere que cada um pense em si e que seja o agente principal de seu desenvolvimento, não apostando fichas que alguém ou alguma organização vá cuidar de seu futuro. Recomenda também mais atenção às ações do que às palavras, uma vez que o comportamento passado é o melhor previsor do comportamento futuro, a compreensão de que as vezes é necessário fazer o mal para se conseguir o bem, o entendimento que ambientes e contextos influenciam o comportamento, que se abandone o pensamento "ou isso ou aquilo", já que nem tudo é trade-off, e que perdoem mas não esqueçam, basicamente uma estratégia de Teoria dos Jogos (Axelrod, 2009). Conclui que a indústria da liderança é caracterizada por desconexões: desconexão entre o que o líder diz e o que faz; entre as prescrições e os traços e comportamentos reais; entre o caráter multidimensional da liderança e as receitas simples, ou simplórias; entre a avaliação da indústria de liderança e a realidade dos ambientes de trabalho; do que as pessoas parecem gostar como histórias reconfortantes e o que deveriam receber, a verdade; da performance e comportamento dos líderes e as consequências por seus atos; e entre o que faz ambientes de trabalho serem melhores e o quanto é implementado.

Pfeffer ao demonstrar as evidências contrárias às prescrições da indústria da liderança está, mais uma vez, buscando uma maior aproximação entre ciência e gestão, entre a academia e o ambiente organizacional. Entretanto, enxergamos um paradoxo final: a indústria da liderança e a gestão empresarial podem ser beneficiadas pelo conhecimento científico, mas enquanto houver demanda para "feel goog leadership literature" haverá fornecedores. As vezes temos que fazer o mal para promover o bem!

\section{REFERÊNCIAS}

Akerlof, G. A., \& Shiller, R. J. (2015). Phishing for Phools: The Economics of Manipulation and Deception. Princeton University Press.

Ariely, D., Bracha, A., \& Meier, S. (2009). Doing Good or Doing Well? Image Motivation and Monetary Incentives in Behaving Prosocially. The American Economic Review, 99(1), 544-555.

Auto Esporte - Volkswagen admite que 11 milhões de carros têm software que frauda testes. ([s.d.]). Recuperado 3 de abril de 2016, de http://g1.globo.com/carros/noticia/2015/09/volkswa gen-admite-que-11-milhoes-de-carros-temsoftware-que-frauda-testes.html 
Axelrod, R. (2009). The Evolution of Cooperation: Revised Edition. Basic Books.

Bateson, M., Nettle, D., \& Roberts, G. (2006). Cues of being watched enhance cooperation in a real-world setting. Biology Letters, 2(3), 412-414. http://doi.org/10.1098/rsbl.2006.0509

Collins, J. (2011). Good to Great: Why Some Companies Make the Leap...And Others Don't. Harper Collins.

Forgas, J. P., Fiedler, K., \& Sedikides, C. (2012). Social Thinking and Interpersonal Behavior. Psychology Press.

Frank, R. H. (2012). The Darwin Economy: Liberty, Competition, and the Common Good. Princeton University Press.

Kahneman, D. (2012). Rápido e devagar: Duas formas de pensar. Editora Objetiva.

Mazar, N., Amir, O., \& Ariely, D. (2008). The Dishonesty of Honest People: A Theory of SelfConcept Maintenance. Journal of Marketing Research, 45(6), 633-644. http://doi.org/10.1509/jmkr.45.6.633

Moskowitz, G. B. (2013). Social Cognition: Understanding Self and Others. Guilford Publications.

Pfeffer, J. (2015). Leadership BS: Fixing Workplaces and Careers One Truth at a Time. HarperCollins.
Pfeffer, J., \& Sutton, R. I. (2013). Hard Facts, Dangerous Half-Truths, and Total Nonsense: Profiting from Evidence-based Management. Harvard Business Press.

Porter, M. (2004). Estrategia Competitiva. Elsevier Brasil.

Rosenzweig, P. (2014). The Halo Effect: . . . and the Eight Other Business Delusions That Deceive Managers. Simon and Schuster.

Squire, L. R., \& Kandel, E. R. (2009). Memory: From Mind to Molecules. Roberts \& Company.

The Constructive, Destructive, and Reconstructive Power of Social Norms. ([s.d.]). Recuperado 31 de março de 2016, de http://pss.sagepub.com/content/18/5/429.short

Trivers, R. (2000). The Elements of a Scientific Theory of Self-Deception. Annals of the New York Academy of Sciences, 907(1), 114-131. http://doi.org/10.1111/j.1749-6632.2000.tb06619.x

Trivers, R. (2010). Deceit and Self-Deception. In P. M. Kappeler \& J. Silk (Orgs.), Mind the Gap (p. 373 393). Springer Berlin Heidelberg. Recuperado de http://link.springer.com/chapter/10.1007/978-3642-02725-3_18

von Hippel, W., \& Trivers, R. (2011). The evolution and psychology of self-deception. Behavioral and Brain Sciences, 34(01), 1-16. http://doi.org/10.1017/S0140525X10001354 